\title{
Laparoscopic Skill Laboratory in Urological Surgery: Tools and Methods for Resident Training
}

\author{
Fabio C. M. Torricelli, Giuliano Guglielmetti, Ricardo J. Duarte, Miguel Srougi \\ Division of Urology, Hospital das Clinicas, University of Sao Paulo Medical School, SP, Brazil
}

\begin{abstract}
Purpose: Laparoscopy has certainly brought considerable benefits to patients, but laparoscopic surgery requires a set of skills different from open surgery, and learning in the operating room may increase surgical time, and even may be harmful to patients. Several training programs have been developed to decrease these potential prejudices.

Purposes: to describe the laparoscopic training program for urological residents of the "Hospital das Clinicas" of the Sao Paulo Medical School, to report urological procedures that are feasible in dry and wet labs, and to perform a critical analysis of the cost-benefit relation of advanced laparoscopic skills laboratory.

Materials and Methods: The laparoscopic skill lab has two virtual simulators, three manual simulators, and four laparoscopic sets for study with a porcine model. The urology residents during their first year attend classes in the virtual and manual simulator and helps the senior urological resident in activities carried out with the laparoscopic sets. During the second year, the urological resident has six periods per week, each period lasting four hours, to perform laparoscopic procedures with a porcine model.

Results: In a training program of ten weeks, one urological resident performs an average of 120 urological procedures. The most common procedures are total nephrectomy $(30 \%)$, bladder suture $(30 \%)$, partial nephrectomy (10\%), pyeloplasty $(10 \%)$, ureteral replacement or transuretero anastomosis $(10 \%)$, and others like adrenalectomy, prostatectomy, and retroperitoneoscopy. These procedures are much quicker and caused less morbidity.

Conclusion: Laparoscopic skills laboratory is a good method for achieving technical ability.
\end{abstract}

Key words: laparoscopy; urology; surgery; training; internship and residency

Int Braz J Urol. 2011; 37: 108-12

\section{INTRODUCTION}

Today, there is no doubt that minimally invasive surgery is the method of choice by patients and surgeons as an approach to most urological surgical pathologies. It has brought considerable benefits to patients such as, smaller incision with better cosmetic results, reduced morbidity, faster recovery, and shorter hospital length of stay (1). Laparoscopic procedures are certainly the most important technique that fulfils these purposes. However, laparoscopic surgery re- quires a different set of skills from open surgery, and learning in the operating room may increase surgical time and even morbidity for patients, moreover, it may be against ethical principles.

The acquisition of basic laparoscopic skills may help beginners who are learning laparoscopic procedures. However, it demands considerable time and dedication from trainees and also requires appropriate teaching facilities. Current training involves the use of box trainers, virtual reality, and animal models. Box trainers with either innate models or animal tis- 
sues lack objective assessment of skill acquisition. Virtual reality simulators have the ability to teach laparoscopic psychomotor skills, and objective assessment is now possible using dexterity-based and video analyses systems (2).

A recent survey (3) of surgery residency program directors revealed that $55 \%$ of surgery training programs have used laparoscopic skills laboratories. Nowadays, a resident in surgery is not allowed to end his/her training program without being able to perform laparoscopic surgery. Numerous protocols for laparoscopic skills training using virtual simulators and animal models have been described in the literature. However, there is a lack of guidelines about the training of an urologist for improving such skills.

The aims of this study were: to describe the laparoscopic training program of the urological residents of the "Hospital das Clinicas" of the Sao Paulo Medical School, University of Sao Paulo, to report urological procedures that are feasible in manual and virtual simulators and with porcine model, and to perform a critical analysis of the cost-benefit relation of advanced laparoscopic skill laboratories.

\section{MATERIALS AND METHODS}

The laparoscopic skill laboratory of the "Hospital das Clinicas" of the Sao Paulo Medical School, University of Sao Paulo, has completed three years in the training of urological residents. The urology department has 15 residents (five residents are admitted per year for a three years course). It has two virtual and three manual simulators and four laparoscopic sets for studying with a porcine model (Figure-1). The materials (laparoscopic equipments and threads) are acquired from donations or are bought at low-cost from retail stores. The animals are donated by a private group. A salaried laboratory manager is responsible for maintaining the laboratory schedule, setting-up, and keeping records of laboratories expenditures. It is estimated that the total direct or indirect expenses funded both by the Government or private sources amount about US\$ $1.0 \mathrm{M}$ in the project and construction of this advanced laparoscopic skill laboratory.

The urological resident, during his first year, attends classes in the virtual and manual simulator once a week (basic skills) and helps the senior urological residents twice a week in activities with the laparoscopic sets. During the second year, the urological resident has six periods per week, each period lasting four hours, for performing laparoscopic procedures with a porcine model. These procedures range from nephrectomy, simple bladder suture or transureteroanastomosis, pyeloplasty, and prostatectomy. Six pigs are available per week and all activities are supervised by one staff surgeon of the laparoscopic group of the urology department. Once a week, this resident also performs one laparoscopic surgery on a patient in the operating room of our service, always in the presence of a physician supervisor. The period for training each resident in our service lasts for ten weeks.

\section{RESULTS}

By the end of the ten week training program one urological resident has carried out an average of 120 urological procedures. The most common procedures are total nephrectomy $(30 \%)$, bladder suture $(30 \%)$, partial nephrectomy $(10 \%)$, pyeloplasty $(10 \%)$, ureteral replacement or transuretero anastomosis $(10 \%)$ and others like adrenalectomy, prostatectomy, and retroperitoneoscopy. All procedures follow the stages of surgery done on human beings with a great similarity.

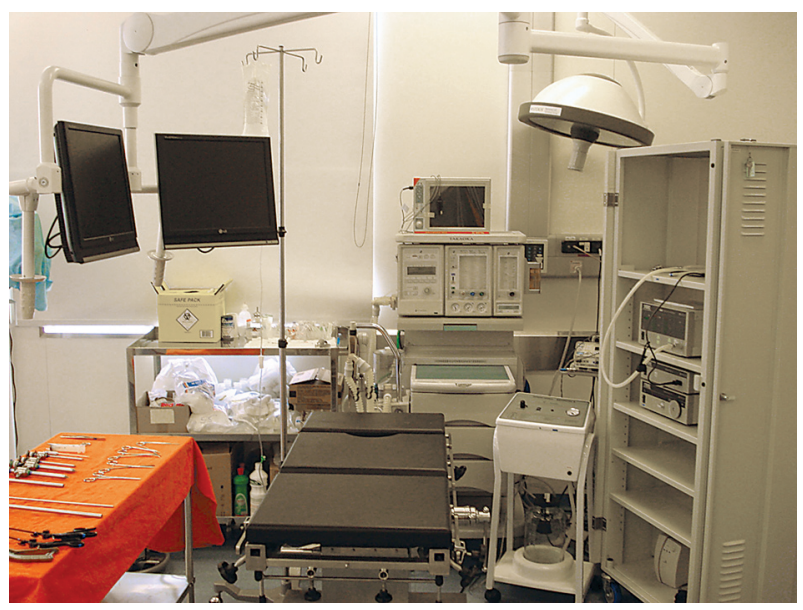

Figure 1 - View of the laparoscopy unit. 
The first year urology resident also improves their skills. After helping the senior resident for ten weeks, they are familiarized with abdominal access and proper trocar placement, is completely adapted to laparoscopic bi-dimensional vision, and is capable of performing basic tasks such as sutures, points and even more complex procedures such as total nephrectomies.

The benefits are evident in the real operating room. The residents become more familiarized with the procedures, the mean time of procedures decreases and fewer complications are observed in the last weeks of the training program. The results are procedures that are quicker, safer, and with less morbidity. It also represents an economy, since less time is spent in the operating room and patients are released earlier.

\section{COMMENTS}

Minimally invasive techniques as laparoscopy are more and more responsible for higher proportion of total surgical procedures performed in operating rooms. Issues such as quality control and patient safety, combined with increasing financial constraints and cost-effective results in operating rooms have to be considered as a need for more skills training laboratories (4). Computer-based virtual reality systems have recently been developed and incorporated into some surgery residents training programs (5-9). A recent survey done in USA revealed that $85 \%$ of general surgery program directors consider skills labs effective for improving operating room performance, however, only $55 \%$ have skills labs. Ninety-nine percent of these have video trainer equipment and $46 \%$ have virtual reality trainer equipment. On average, residents train for 0.8 hours per week (range 0 to 6 ), and this training is mandatory for $55 \%$ and supervised for $73 \%$. The mean development cost was US\$133,000 (3). This period of training is shorter than the one proposed in our laparoscopic skill lab, where one resident spent more than 20 hours per week for a period of ten weeks.

Surgical skills laboratories provide residents with the opportunity to acquire technical skills in a low stressed and stimulated environment, while focusing on learning and repeating key stages of procedures in a setting where they are able to reduce their learning curve with the goal of decreasing potential harm to patients (10).

Some authors have reported the benefits of laparoscopic training program. Vlaovic et al. (11) reported their experience with 101 urologists submitted to a one-week laparoscopic training program and concluded that it significantly improved laparoscopic skills. Pareek et al. (12) reported the results of a 2-day course of laparoscopic training. Of the participants that answered the survey, 97\% reported that their laparoscopic practice had expanded after taking course. Condous et al. (13) in a prospective observational study with 24 surgeons concluded that laparoscopic skills workshops could improve both knowledge and motor skill.

Several studies have tried to compare the tools now available for training and development of laparoscopic skills. Manda et al. (14) compared the combination of virtual reality and box training. Twenty-four students were grouped according to four training methods: virtual reality training, inanimate box training, a combination of both and no training. Post hoc analyses showed statistically significant differences between the participants with both trainers and control subjects. Combination of virtual reality training and inanimate box training leads to a better laparoscopic skill acquisition than either training method alone or no training at all. Munz et al. (4) compared the virtual reality simulator with the classical box trainer. Again twenty-four beginners were divided into three groups: virtual reality simulator, box trainer and no training and the authors found that both trained groups made significant improvements in all parameters measured, however there was no difference between the tools of training. They concluded that they are equally effective in teaching psychomotor skills, but a large cohort may show different results. We were not able to compare the development of our residents, since the training was basically performed in laparoscopic sets, where objective evaluation is very limited. Our impression is that the benefits are real with a great increase in laparoscopic skills of our residents who become more prepared for surgery in the operating room. Moreover, porcine models made it possible to perform a larger number of urological procedures. Perhaps in a future 
study we may be able to compare mean surgical time, blood loss, and other parameters before, during, and after our training program, in surgeries performed in the lab and in the real operating room.

The studies available today are very limited as far as cost analysis is concerned. Berg et al. (10) reported that they are able to provide surgical skills training for about $\$ 1,000$ per resident per year; however the costs of donated services, equipment, and supplies were not estimated. We have a similar problem in our cost assessment, because our material was acquired from donations or was bought at low-cost from retail stores.

\section{CONCLUSION}

Laparoscopic skills laboratory are an effective way for achieving technical skills in an optimal environment and with the potential of being less harmful to patients.

\section{CONFLICT OF INTEREST}

None declared.

\section{REFERENCES}

1. Darzi A, Mackay S: Recent advances in minimal access surgery. BMJ. 2002; 324: 31-4.

2. Aggarwal R, Moorthy K, Darzi A: Laparoscopic skills training and assessment. Br J Surg. 2004; 91: 1549-58.

3. Korndorffer JR Jr, Stefanidis D, Scott DJ: Laparoscopic skills laboratories: current assessment and a call for resident training standards. Am J Surg. 2006; 191: 17-22.

4. Munz Y, Kumar BD, Moorthy K, Bann S, Darzi A: Laparoscopic virtual reality and box trainers: is one superior to the other? Surg Endosc. 2004; 18: 485-94.

5. Lehmann KS, Ritz JP, Maass H, Cakmak HK, Kuehnapfel UG, Germer CT, et al.: A prospective randomized study to test the transfer of basic psychomotor skills from virtual reality to physical reality in a comparable training setting. Ann Surg. 2005; 241: 442-9.

6. Youngblood PL, Srivastava S, Curet M, Heinrichs WL, Dev P, Wren SM: Comparison of training on two laparoscopic simulators and assessment of skills transfer to surgical performance. J Am Coll Surg. 2005; 200: 546-51.

7. Conn J: The games doctors play. Physicians are turning to high-tech simulators to practice their clinical techniques. Even video-game skills prove valuable in the OR. Mod Healthc. 2004; 34: 32-3.

8. Grantcharov TP, Kristiansen VB, Bendix J, Bardram L, Rosenberg J, Funch-Jensen P: Randomized clinical trial of virtual reality simulation for laparoscopic skills training. Br J Surg. 2004; 91: 146-50.

9. Gallagher AG, Ritter EM, Champion H, Higgins G, Fried MP, Moses G, et al.: Virtual reality simulation for the operating room: proficiency-based training as a paradigm shift in surgical skills training. Ann Surg. 2005; 241: 364-72.

10. Berg DA, Milner RE, Fisher CA, Goldberg AJ, Dempsey DT, Grewal H: A cost-effective approach to establishing a surgical skills laboratory. Surgery. 2007; 142: 712-21.

11. Vlaovic PD, Sargent ER, Boker JR, Corica FA, Chou DS, Abdelshehid CS, et al.: Immediate impact of an intensive one-week laparoscopy training program on laparoscopic skills among postgraduate urologists. JSLS. 2008; 12: 1-8.

12. Pareek G, Hedican SP, Bishoff JT, Shichman SJ, Wolf JS Jr, Nakada SY: Skills-based laparoscopy training demonstrates long-term transfer of clinical laparoscopic practice: additional follow-up. Urology. 2008; 72: 265-7.

13. Condous G, Alhamdan D, Bignardi T, VAN Calster B, VAN Huffel S, Timmerman D, et al.: The value of laparoscopic skills courses. Aust N Z J Obstet Gynaecol. 2009; 49: 312-5.

14. Madan AK, Frantzides CT: Prospective randomized controlled trial of laparoscopic trainers for basic laparoscopic skills acquisition. Surg Endosc. 2007; 21: 209-13.

\section{Accepted after revision: \\ March 20, 2010}

\section{Correspondence address:}

Dr. Fábio César Miranda Torricelli

Av. Vereador José Diniz, 3300/ 208

Sao Paulo, SP, 04604-006, Brazil

E-mail: fabio_torri@yahoo.com.br 


\section{EDITORIAL COMMENT}

Authors present their experience with a resident laparoscopic skill laboratory and a formal training program for urology residents. It is our belief as well that these programs should be present in all urology residency programs. There is no discussion about the important and definitive role of laparoscopic surgery, and formal training programs are essential. Several randomized studies have evaluated the role of these training programs (1), and they help to make surgical procedures faster and more precise. Additional measures, as preoperative warm-up also seems to be of value (2). Expensive virtual reality simulators are interesting, but far from being necessary. The Hospital das Clinicas' center is interesting, and an honored model. We believe that similar but cheaper models are possible and as effective as expensive centers, and are important to make these structures accessible throughout Brazil. A progressive approach to simulation with increasing complexity and a well-designed training curriculum is definitively the best model. We have adopted the initial step of the curriculum of our residents-in-training at a dry lab, through exercises that can be objectively evaluated (time and perfection to perform each exercise). The second step is to performed specific surgical procedures, such as ureteral, intestinal, urethro-vesical anastomoses, pyeloplasty, nephrectomy, etc., either in the dry lab or in porcine models. It is important to mention however, that animal training should be reduced to the minimum necessary, for ethical reasons; and the third step is to observe, participate and perform real surgical procedures. Additionally, these training models can also help to maintain skills for surgeons already in practice.

\section{REFERENCES}

1. Lachapelle K: Teaching technical skills using medical simulation: a new frontier. Mcgill J Med. 2007; 10: 149-51.

2. Korkes F., Wroclawski ML., Tavares A. Castro-Neves Neto O, Tobias-Machado M, Pompeo ACL, Wroclawski ER: Video game as a preoperative warm-up for laparoscopic surgery. Einstein 2009; 7: 462-4.

Dr. Marcos Tobias-Machado ABC Medical School Sao Paulo, SP, Brazil E-mail:tobias-machado@uol.com.br

Dr. Fernando Korkes ABC Medical School Sao Paulo, SP, Brazil 